\title{
Exogenous Lung Surfactant Decreases Interleukin-8 Production and Increases Leukocytes Population and Total Immunoglobulins in Rabbits
}

Sepideh Yamini (MSc)

Department of Cell Biology and

Molecular Genetics Tendency, Islamic

Azad University, Tehran Medical

Science Branch, Tehran, Iran

Zohre Eftekhari (PhD)

Research \& Production Complex,

Pasteur Institute of Iran, Tehran, Iran

Mohammad Reza Mokhber Dezfouli $(\mathrm{PhD})$

Department of Clinical Sciences,

Faculty of Veterinary Medicine,

University of Tehran, Tehran, Iran \&

Institute of Biomedical Research,

University of Tehran, Tehran, Iran

Babak Beikzadeh (PhD)

Department of Microbiology and Immunology, Faculty of Veterinary

Medicine, University of Tehran,

Tehran, Iran; and Academic Center for

Education, Culture and Research

(ACECR), Tehran Organization,

Tehran, Iran

Parvane Mehrbod (PhD)

Influenza and Other Respiratory

Viruses Department, Pasteur Institute

of Iran, Tehran, Iran

Corresponding author: Zohre

Eftekhari

Tel: +98-9143126149

Email: eftekharivet@gmail.com ,

Address: Research \& Production

Complex, Pasteur Institute of Iran,

Tehran- Iran

Received: 11 Jan 2019

Revised: 31 Jul 2019

Accepted: 17 Aug 2019

\section{(c) (i) (9)}

This work is licensed under a Creative

Commons Attribution 4.0 License.

\section{ABSTRACT}

Background and Objectives: Exogenous lung surfactant (ELS) obtained from extraction of bronchoalveolar lavage fluid, is prescribed in some respiratory disorders, which could affect production of lung-related cytokines. Interleukin-8 (IL-8) is a major cytokine that could affect severity of lung diseases. In this study, we investigate the possible impact of ELS on IL-8 expression, hematological parameters and $\lg 6$ and IgVI levels in rabbits.

Methods: ELS solution obtained from fresh calf's lung bronchoalveolar lavage was infused into the lungs of five rabbits via tracheal tube. Blood samples were collected before and after ELS treatment for 30 days.

Results: Serum IL-8 levels decreased over time following ELS administration. IL-8 expression also decreased after exposure to ELS, but leukocytes count increased significantly 24, 48 and 72 hours after ELS therapy compared to baseline values $(\mathrm{P}<0.05)$. IgM level increased significantly 72 hours after the ELS therapy and returned to normal range at the end of study.

Conclusion: 0ur findings suggest that ELS could down-regulate IL-8 expression in mononuclear cells while increasing leukocytes population and total immunoglobulins level, which can trigger immune responses without lung damage. However, further studies should be performed to confirm the regulatory effects of ELS on inflammatory responses in lung diseases.

Keywords: Exogenous lung surfactant, IL-8, Immunoglobulins.

This paper should be cited as: Yamini S, Eftekhari Z, Mokhber Dezfouli MR, Beikzadeh B, Mehrbod P[Exogenous Lung Surfactant Decreases Interleukin-8 Production and Increases Leukocytes Population and Total Immunoglobulins in Rabbits ]. mljgoums. 2019; 13(6): 17-22 


\section{INTRODUCTION}

The mammalian lung surfactant components include phospholipids, neutral lipids and four proteins that prevent atelectasis by reducing surface tension at the alveolar (1, 2). In addition, surfactant proteins can be stimulated to produce pro-inflammatory cytokines such as TNF- $\alpha$, interleukin 1 beta, interleukin -6 and interleukin-8 (IL-8) by pneumocytes (type-II cells) or monocytes (3, 4). Natural surfactant is synthesized by alveolar type II cells and stored in intracellular lamellar inclusion bodies before release into the alveolar space (5). Inflammation plays a major role in lung dysfunction (6). Among pro-inflammatory cytokines, a great deal of attention has been focused on chemokines that are mainly involved in controlling the leukocytes migration to inflammation sites (7). It has been suggested that IL-8 play a key role in some lung disorders, including respiratory infections and fibrotic lung diseases (8-10). Immune cells such as neutrophils and monocytes are involved in pathogenesis of several inflammatory lung diseases, including acute respiratory distress syndrome, chronic obstructive pulmonary disease and asthma. IL8 is a powerful neutrophil-recruiting chemokine. Previous studies have shown that presence of $\mathrm{IL}-8$ in clinical samples is associated with lung disease. Therefore, it is proposed that controlling IL-8 level may be a feasible therapeutic strategy for management of lung disease $(11,12)$.

Exogenous lung surfactant (ELS) obtained from natural sources is a valuable drug candidate in neonatal respiratory distress syndrome and other respiratory disorders (13). However, the effect of ELS on IL-8 is still unknown. The present study was designed to evaluate effects of ELS on IL-8 level and gene expression in peripheral blood mononuclear cells (PBMC) cells, leukocytes population and total serum $\operatorname{IgG}$ and $\operatorname{IgM}$ levels of healthy rabbits.

\section{MATERIALS AND METHODS}

Five healthy male New Zealand White Rabbits (Oryctolagus cuniculus) weighing 2.5$3 \mathrm{~kg}$ were purchased from the Animal Sciences Laboratory of Pasteur Institute of Iran. All experimental procedures involving animals were approved by the Ethics Committee of Faculty of Veterinary Medicine, University of Tehran, Iran. The health of selected rabbits was approved by clinical examinations and hematology evaluation. The animals were kept under adaptation period for 48 hours prior to commencement of the procedure.

ELS was obtained by extracting bronchoalveolar lavage fluid of freshly slaughtered calf's lungs without macroscopic lesions. Lavage fluids from several calves were combined, cells and debris were removed and cell-free bronchoalveolar lavage fluid supernatants were centrifuged at 20,000 $\mathrm{g}$ for $60 \mathrm{~min}$ at $4{ }^{\circ} \mathrm{C}$ to separate crude surfactant pellets (CSP)(4). Crude calf lung surfactant was obtained by extraction of CSP by a modified Bligh and Dyer method (14). Afterwards, lower phase was concentrated using rotary evaporator $\left(120 \mathrm{rpm}\right.$, at $\left.20{ }^{\circ} \mathrm{C}\right)$ (4). Then, an active pharmaceutical ingredient was formulated by adding dipalmitoylphosphatidylcholine(Sigma, USA) and palmitic acid (Merck Millipore, USA). Finally, a suspension was made by adding $0.9 \% \mathrm{NaCl}$.

The rabbits were anesthetized by intramuscular injection of $5 \mathrm{mg} / \mathrm{kg}$ Xylazine $2 \%$ (Holland Interchemic Co., Germany) and $35 \mathrm{mg} / \mathrm{kg}$ Ketamin (Trittau Co., Germany) (4). After placing the tracheal tube, positioning was confirmed by end-tidal $\mathrm{CO}_{2}$ monitoring. Bronchoalveolar lavage catheter was inserted via the tracheal tube and the ELS solution (4 $\mathrm{ml} / \mathrm{kg} \mathrm{BW}$ ) was infused into the lungs $(4,7)$. Blood samples were collected into $10 \mathrm{ml}$ sterile heparinized tubes before and after administration of ELS for 30 days (4).

Two ml of peripheral blood were collected for hematological assessment (15). Leukocytes count was determined by Neubauer chamber and leukocytes differential count was determined by the blood smear method (15, 16).

The collected blood samples diluted with sterile phosphate buffer saline (Sigma, Germany) were added gently to $5 \mathrm{ml}$ of Ficoll Histopaque (Biowest Co., Germany). The PBMCs formed in the inter-phase between Histopaque and the medium were aspirated and resuspended in Roswell Park Memorial Institute 1640 medium $\left(\mathrm{Gibco}^{\circledR}\right.$, UK) containing $20 \%$ fetal bovine serum (Gibco ${ }^{\circledR}$, UK) and antibiotic (Penicillin/Streptomycin $0.01 \%$, Sigma, Germany). Then, $0.5 \mathrm{ml}$ of cell suspension $\left(10^{6} \mathrm{cell} / \mathrm{ml}\right)$ was added to each 
well of a 24-well plate (NEST®, China) (4). PBMCs supernatant was harvested and analyzed for IL-8 by enzyme-linked immunosorbent assay (ELISA) using commercially available kits (MyBioSource Inc., USA). Serum levels of total IgM and IgG were also evaluated using ELISA kits (MyBioSource Inc., USA). Total RNA was extracted from the isolated cells using the RNX-plus kit (CinnaGen Inc., Iran) according to the manufacturer's protocol. Quantity of the extracted RNA was evaluated by a Nanodrop 2000 spectrophotometer. The reverse transcription process was carried out using CinnaGen First Strand cDNA synthesis and random hexamer primers $(4,17)$. The primers were designed using the AlleleID software and then verified by BLAST (NCBI databases). Table 1 shows the sequence of the primers used in the study. Finally, real-time PCR was performed for gene expression analysis and cytokine quantification. Real-time PCR was performed using Light Cycler Fast Start DNA Master Syber Green Kit and cDNA dilution in diethyl pyrocarbonate water (Table 2). Details of the cycling conditions are presented in table 3. Fluorescence of SYBR green dye bound to double-stranded DNA was measured at 530 nm (Light Cycler fluorescence channel F1). A melting curve analysis was performed to evaluate the possibility of non-specific amplification or primer-dimer formation (4) (Figure 1). B-actin was used as the house keeping gene in the real-time PCR experiment. The obtained data were analyzed with repeated measures ANOVA, paired t-test and LSD post hoc test. Moreover, analysis of data was performed on the basis of Delta-Delta cT from the device and the REST2009 software. All statistical analyses were performed at significance level of 0.05 .

\section{RESULTS}

As shown in table 4, lymphocytes count increased significantly 24,48 and 72 hours after the ELS treatment compared to therapy). baseline ( $\mathrm{P}=0.04)$, but at days 7 and 30 , it returned to normal range. Monocyte count also increased significantly during the study period $(\mathrm{P}=0.04)$.

The number of monocytes differed significantly between the baseline value and 24, 48 and 72 hours post-ELS administration $(\mathrm{P}=0.035)$.

Compared to baseline, the number of leukocytes was significantly higher 24 and 48 hours after the ELS administration $(\mathrm{P}=0.045)$. Nonetheless, the eosinophil and basophil counts did not change notably in response to ELS therapy (Table 4).

During the study, the level of IgG increased and this increase was statistically significant at day 30 post-ELS therapy $(15.31 \pm 0.93 \mathrm{mg} / \mathrm{ml})$ compared to baseline $(10.62 \pm 0.2 \mathrm{mg} / \mathrm{ml})$. IgM level increased following ELS therapy, reaching its maximum level after 7 days $(876 \pm 23.79 \mathrm{pg} / \mathrm{ml})$ but returning to normal range at the end of study $(384 \pm 41.04 \mathrm{pg} / \mathrm{ml})$.

IL-8 level changed significantly following ELS therapy $(\mathrm{P}=0.035)$.

The content of IL-8 at days 2 and 3 decreased significantly. The IL-8 concentration was lowest at day 2 (Figure 2).

The melting curves of IL-8 gene expression were plotted by target gene amplification using real-time PCR (Figure $1)$.

The results showed that the expression of IL-8 gene decreased 24 hours after the ELS therapy $(0.084 \pm 0.04$ in beginning of study and $0.085 \pm 0.03424$ hours after the treatment) until reaching its minimum value 48 hours post-treatment $(0.064 \pm 0.12$ at baseline and $0.053 \pm 0.0448$ hours after ELS

Table 1- Sequence of the primers used in the study

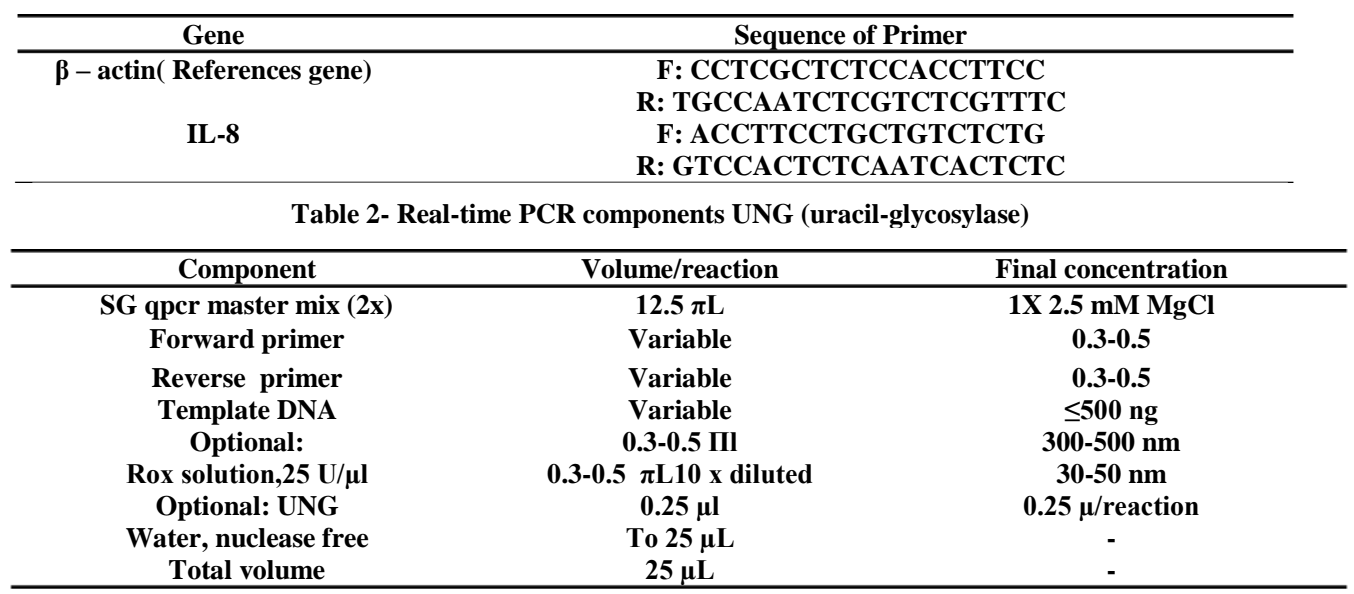


Figure 1- Melting curve of IL-8 48 hours after the injection of ELS
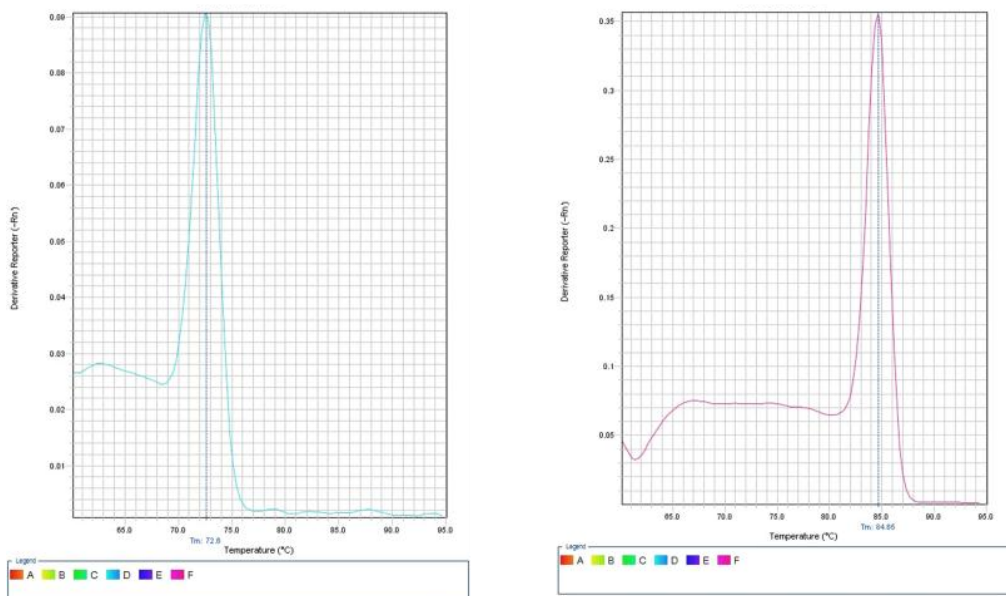

Figure 2- IL-8 level in PBMC supernatant at baseline and after ELS treatment.

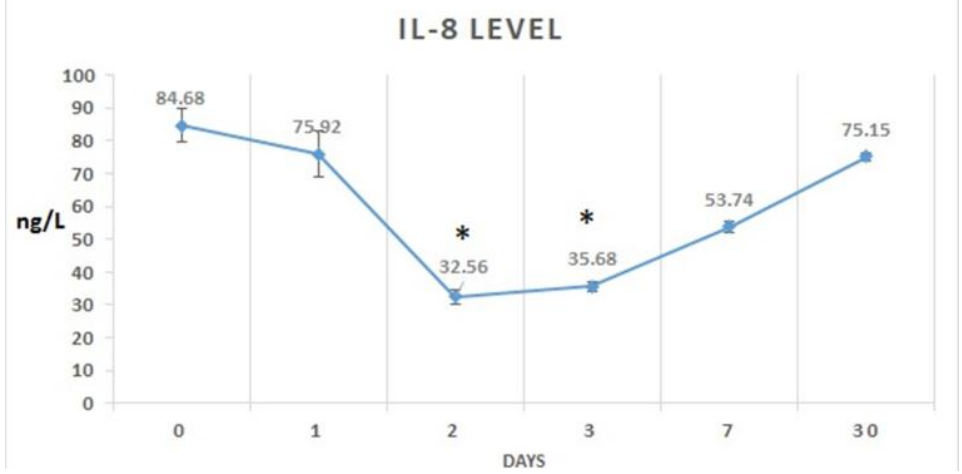

* represents significant difference from baseline values.

Table 3- Real-time PCR cvcling conditions

\begin{tabular}{|c|c|c|c|}
\hline Cycle & Time & Temperature & Step \\
\hline 1 & $2 \mathrm{~min}$ & $50^{\circ} \mathrm{C}$ & $\begin{array}{c}\text { Optional: } \\
\text { UNG pretreatment }\end{array}$ \\
\hline \multirow{2}{*}{$\begin{array}{c}1 \\
34-35\end{array}$} & $10 \mathrm{~min}$ & $95^{\circ} \mathrm{C}$ & Initial denaturation \\
\hline & 30s & $50-60{ }^{\circ} \mathrm{C}$ & Annealing \\
\hline & $15 \mathrm{~s}$ & $\mathbf{X}^{0} \mathrm{C}$ & Optional data acquisition \\
\hline 1 & Indefinite & $4^{\circ} \mathrm{C}$ & Cooling \\
\hline
\end{tabular}

Table 4- Changes in hematological parameters during the study period

\begin{tabular}{|c|c|c|c|c|c|c|}
\hline Cells & $\begin{array}{c}\text { Mean } \pm \text { SD } \\
\text { Baseline) }\end{array}$ & $\begin{array}{l}\text { Mean } \pm \text { SD } \\
\text { ( } 24 \text { hours) }\end{array}$ & $\begin{array}{l}\text { Mean } \pm \text { SD } \\
(48 \text { hours) }\end{array}$ & $\begin{array}{l}\text { Mean } \pm \text { SD } \\
(72 \text { hours) }\end{array}$ & $\begin{array}{c}\text { Mean } \pm \text { SD } \\
\text { (7 days) }\end{array}$ & $\begin{array}{c}\text { Mean } \pm \text { SD } \\
\text { (30 days) }\end{array}$ \\
\hline Eosinophils (cell/ $\mu \mathrm{L})$ & $114 \pm 0.1$ & $142 \pm 7.5$ & $128.4 \pm 4.88$ & $118.8 \pm 3.81$ & $115.6 \pm 2.31$ & $116 \pm 4.0$ \\
\hline Basophils $($ cell $/ \mu \mathrm{L})$ & $97.3 \pm 1.2$ & $101.8 \pm 4.52$ & $100.4 \pm 5.73$ & $97.2 \pm 7.17$ & $96.8 \pm 7.3$ & $99.4 \pm 3.57$ \\
\hline Monocytes (cell/ $\mu \mathrm{L})$ & $76.2 \pm 1.02$ & $203.4 \pm 5.32$ & $400 \pm 17.2$ & $193.4 \pm 5.87$ & $99.2 \pm 3.68$ & $78.8 \pm 3.032$ \\
\hline Lymphocytes $($ cell $/ \mu \mathrm{L})$ & $3840 \pm 16.46$ & $6612 \pm 15.2$ & $5435.1 \pm 12.53$ & $5228.4 \pm 17$ & $4336 \pm 25.5$ & $3921.4 \pm 1.7$ \\
\hline Leukocytes $(\operatorname{cell} / \mu \mathrm{L})$ & $5020 \pm 102.1$ & $7180 \pm 106.77$ & $6640 \pm 510.48$ & $6120 \pm 86.02$ & $5060 \pm 107.70$ & $4840 \pm 196.46$ \\
\hline
\end{tabular}

SD: Standard Deviation 


\section{DISCUSSION}

Stimulation of monocytes and alveolar macrophages as well as cytokine release in the presence of an infectious pathogen in the respiratory tract or inflammation can alter the phospholipid content of surfactant (9). It can therefore be assumed that the monocytes activated production of lymphocytes and some cytokines such as IL-8 to help the inflammation process (3). In the presence study, we demonstrated that ELS can decrease IL-8 expression and release from PBMC. In addition, hematological findings indicated that ELS therapy increased the total leukocytes and monocytes populations. Based on the obtained results, although monocyte and lymphocyte contents increased expectedly, one of the main inflammatory cytokines (IL-8) decreased following the ELS therapy. Similar to our findings, previous investigations reported that exogenous surfactant therapy could inhibit inflammatory responses and induce monocyte and cytokines production $(18,19)$. ELS could be used as a transport medium for anti-IL-8 antibodies in order to block chemotactic and inflammatory effects of this cytokine (20). Based on previous studies, ELS prevent leukocytes infiltration into the lungs, but our findings indicated an increase in total leukocytes in peripheral blood (20). But in some cases the expression of the IL- 8 gene seems to be prevented by certain components

\section{REFERENCES}

1. Notter RH, Wang Z, Egan E, Holm B. Componentspecific surface and physiological activity in bovinederived lung surfactants. Chemistry and Physics of Lipids. 2002; 114(1): 21-34.

2. Bissinger RL, Carlson CA. Surfactant. Newborn and Infant Nursing Reviews. 2006;6(2):87-93.

3. Banchereau J. Cells and Cytokines in Lung Inflammation. Mediators Inflamm. 1994; 3(1): 61-99.

4. Aliverdilo M MDM, Eftekhari Z, Paryan Mahdi. Evaluation of Lung Surfactant on Gene Expression of MCP-1 in Peripheral Blood Mononuclear Cells in Rabbit Model. Journal Of Animal Biology 2017;9 (4):67-77.

5. Frerking I, Günther A, Seeger W, Pison U. Pulmonary surfactant: functions, abnormalities and therapeutic options. Intensive care med. 2001; 27(11): 1699-717.

6. Alcorn JL. Innate Immunity and Pulmonary Inflammation: A Balance Between Protection and Disease. Translational Inflammation: Elsevier; 2019;15375.

7. Mokhber Dezfouli MR, Eftekhari Z, Heidari Sureshjani M, Dehghan MM, Dousti M. The hydrophilic proteins of lung surfactant as a prognostic marker in experimental pneumonia. Iranian Journal of Veterinary Medicine. 2017; 11(1): 1-8. of the inflammatory situation (21). As a foreign agent, ELS increased total serum IgM and IgG, which could have immunostimulatory effects against pathogens. Surfactant proteins can aggregate and bind to IgG and consequently contribute to neutrophil phagocytosis. $(10,22)$.

\section{CONCLUSION}

Our results revealed that ELS therapy decreases IL-8 expression and increases leukocytes population and immunoglobulins level in peripheral blood. Altogether, these results suggest that ELS could stimulate the immune system in the lungs without triggering an inflammatory response. Thus, it is recommended to perform further studies on the immunoprotective and potential therapeutic effects of ELS in treatment of respiratory diseases.

\section{ACKNOWLEDGMENTS}

The authors wish to express their sincere gratitude to the Institute of Biomedical Research of Veterinary Medicine, University of Tehran and Persian Darou Alborz Research and Technology for funding this project.

\section{CONFLICT OF INTEREST}

The authors declare that there is no conflict of interest.

8. Goodyear A, Jones A, Troyer R, Bielefeldt-Ohmann $\mathrm{H}$, Dow SJTjoi. Critical protective role for $M C P-1$ in pneumonic Burkholderia mallei infection. J Immunol. 2010; 184(3): 1445-54. doi: 10.4049/jimmunol.0900411.

9. Brogden KAJAvL. Changes in pulmonary surfactant during bacterial pneumonia. Antonie Van Leeuwenhoek. 1991; 59(4): 215-23.

10. Chida S, Phelps DS, Soll RF, Taeusch HWJP. Surfactant proteins and anti-surfactant antibodies in sera from infants with respiratory distress syndrome with and without surfactant treatment. Pediatrics. 1991; 88(1): 849.

11. Meloni F, Alberti A, Bulgheroni A, Lupi A, Paschetto E, Bianco AM, et al. Surfactant apoprotein A modulates interleukin-8 and monocyte chemotactic peptide-1 production. Eur Respir J. 2002; 19(6): 112835.

12. Tanaka N, Watanabe J, Kitamura T, Yamada Y, Kanegasaki S, Nakata KJFl. Lungs of patients with idiopathic pulmonary alveolar proteinosis express a factor which neutralizes granulocyte-macrophage colony stimulating factor. FEBS Lett. 1999; 442(2-3): 246-50.. 
13. Zhang L, Cao H-Y, Zhao S, Yuan L-J, Han D, Jiang $\mathrm{H}$, et al. Effect of exogenous pulmonary surfactants on mortality rate in neonatal respiratory distress syndrome: a network meta-analysis of randomized controlled trials. Pulm Pharmacol Ther. 2015; 34: 46-54. doi: 10.1016/j.pupt.2015.08.005.

14. Bligh EG, Dyer WJ. A rapid method of total lipid extraction and purification. Can J Biochem Physiol. 1959; 37(8): 911-7.

15. Molina E, González-Redondo P, Moreno-Rojas R, Montero-Quintero K, Chirinos-Quintero N, SánchezUrdaneta AJJoap, et al. Evaluation of haematological, serum biochemical and histopathological parameters of growing rabbits fed Amaranthus dubius. J Anim Physiol Anim Nutr (Berl). 2018 ; 102(2): e525-e533. doi: 10.1111/jpn.12791.

16. Bush B. Manual de laboratorio veterinario de análisis clínico: Acribia. 1982; 468.

17. Ramos-Payán R, Aguilar-Medina M, Estrada-Parra S, González-y-Merchand J, Favila-Castillo L, MonroyOstria A, et al. Quantification of Cytokine Gene Expression Using an Economical Real-Time Polymerase Chain Reaction Method Based on SYBR® Green I. Scand J Immunol. 2003; 57(5): 439-45.
18. Geertsma M, Teeuw W, Nibbering P, Van Furth RJI. Pulmonary surfactant inhibits activation of human monocytes by recombinant interferon-gamma. Immunology. 1994; 82(3): 450-6.

19. Amigoni A, Pettenazzo A, Stritoni V, Circelli MJCdi. Surfactants in acute respiratory distress syndrome in infants and children: past, present and future. Clin Drug Investig. 2017; 37(8): 729-736. doi: 10.1007/s40261017-0532-1.

20. Mikolka P, Kopincova J, Kosutova P, Kolomaznik M, Calkovska A, Mokra DJElr. Anti-IL-8 antibody potentiates the effect of exogenous surfactant in respiratory failure caused by meconium aspiration. Exp Lung Res. 2018; 44(1): 40-50. doi: 10.1080/01902148.2017.1420272.

21. Abate W, Alghaithy AA, Parton J, Jones KP, Jackson SKJJolr. Surfactant lipids regulate LPS-induced interleukin-8 production in A549 lung epithelial cells by inhibiting translocation of TLR4 into lipid raft domains. J Lipid Res. 2010; 51(2): 334-44. doi: 10.1194/jlr.M000513.

22. Toews G. Cytokines and the lung. European Respiratory Journal. 2001; 18(34 suppl): 3s-17s. 